\title{
Fetal Outcome Varies with Different Grades of Placental Abruption
}

\author{
Z SAADIA A Z KHAN F NAHID \\ Department of Gynaecology \& Obstetrics, Fatima Jinnah Medical College/Sir Ganga Ram Hospital \\ Department of Surgery, Fatima Jinnah Medical College/Sir Ganga Ram Hospital, Lahore \\ Correspondence to Dr. Zaheera Saadia, E. mail: Zaheerasaadia@ hotmail.com.
}

\begin{abstract}
This is a prospective study carried out in Gynae unit-1 of Sir Ganga Ram Hospital, Lahore over a time period of one year. We aimed to find out the prevalence of abruptio placenta in the hospital population and compare the fetal outcome with different grades of placental abruption. Student $t$ test was applied to assess the degree of significance. $P$ value $<0.05$ was considered as significant. Complications observed were intrauterine death (IUD), Intrauterine growth retardation (IUGR), Prematurity and fetal anemia. Placental abruption accounted for $2 \%$ of hospital obstetrical population. Adverse fetal outcome was observed with Grade3-4 abruption as compared to abruption of Grade 0-1. Statistically significant numbers of fetuses had no complication with Grade 0-1 abruption and were delivered in good condition (table-1). We concluded that a more aggressive approach is required to manage abruption of Grade 3-4 and observational strategy should be considered for Grade 0-1.
\end{abstract}

Key words: IUD, IUGR

Placental abruption is defined as bleeding following premature separation of a normally situated placenta. The incidence varies from $0.49-1.8 \%{ }^{1}$. It is a major contributor to obstetrical hemorrhage and a major cause of perinatal mortality in developing countries. In a study conducted at Services hospital Lahore, the frequency of abruptio placenta was $1.2 \%$ of all hospital deliveries ${ }^{2}$. High parity, Pre-eclamptic toxemia and hypertension are significant etiological determinants of abruptio placenta ${ }^{3}$. Other factors that can lead to placental abruption are trauma, multiple pregnancy, polyhydramnios, artificial rupture of membranes, smoking and cocaine abuse.

Placental abruption is significantly associated with high perinatal mortality rate ${ }^{4}$. Ozuma reported from Nigeria that placental abruption has a PNM rate of $5.8 \%{ }^{5}$. The risk of still birth is dramatically increased from severe abruption but preterm delivery is commoner in women with lesser degrees of placental separation ${ }^{6}$. There is a need for adequate antenatal and intrapartum care to eliminate the maternal and fetal complications of this obstetrical enigma ${ }^{5}$. We aimed to find out the prevalence of placental abruption in hospital population and to compare the fetal outcome in relation to different grades of abruption.

\section{Subjects and methods}

This is a prospective study conducted over a period of one year from Jan - Dec 99. All the patients admitted in Labour room of Sir Ganga Ram Hospital over 28 weeks of gestation were included in the study. They were divided into groups on the basis of following clinical criteria ${ }^{7}$.

Fetal condition was assessed at the time of birth by the pediatrician. Patients were divided into two groups. Group1 included women who had abruption of Grade $0-1$. Group-2 included women with abruption of Grade 3-4. Comparison of the fetal outcome amongst both groups was made by applying student $\mathrm{t}$ test. $\mathrm{P}$ value $<0.05$ was considered as significant.
Grade
Description
0 Asymptomatic-When a small retroplacental clot is discovered
1 There is vaginal bleeding. Uterine tetyany and tenderness may be present. There are no signs of maternal shock or fetal distress
2 External vaginal bleeding may or may not be present. There are no signs of maternal shock. Signs of fetal distress are present.
3 External bleeding may or may not be present.
There is marked uterine tatany, yielding a
board like consistency on palpation. Persistent
abdominal pain, maternal shock and fetal
demise are present. Coagulopathy may
become evident in $30 \%$ cases.

Results

Distribution of patients with placental abruption in the hospital population

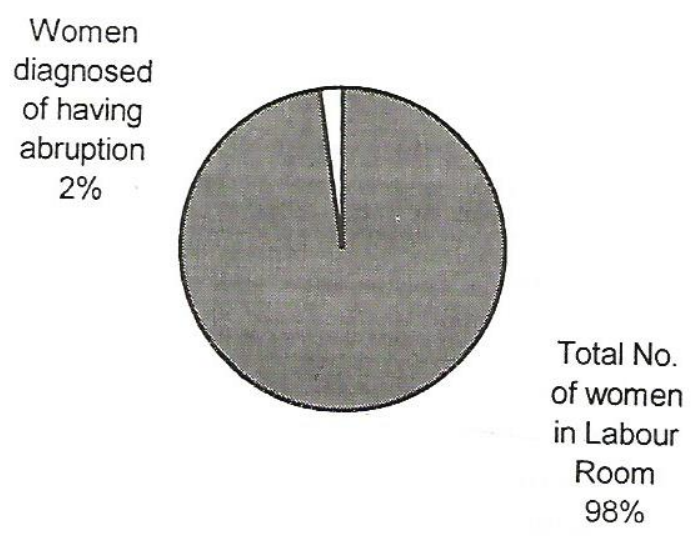

Percentage of women with abruptio placentae in 2 years hospital population $=2$ 
Table 1 Comparison of fetal outcome with different grades of placental abruption (percentile distribution):

\begin{tabular}{lllll}
\hline Outcome & $\begin{array}{l}\text { Group 1 } \\
(\text { Grade } 0- \\
1)(\mathrm{n}=19)\end{array}$ & $\begin{array}{l}\text { (iroup-2 } \\
(\text { (Grade } 2-3) \\
(\mathrm{n}=60)\end{array}$ & $\begin{array}{l}\text { P- } \\
\text { Value }\end{array}$ & $\begin{array}{l}\text { Signifi- } \\
\text { cance }\end{array}$ \\
\hline $\begin{array}{l}\text { Intrauterine death } \\
\text { Prematurity }\end{array}$ & 10.5 & 26.6 & 2.12 & $\mathrm{~S}$ \\
$\begin{array}{l}\text { Intrauterine } \\
\text { growth }\end{array}$ & 10.5 & 28.3 & 1.95 & $\mathrm{~S}$ \\
retardation & 15.7 & 20.0 & 0.438 & $\mathrm{NS}$ \\
Anemia & & & & \\
Noproblem & 5.26 & 21.6 & 2.21 & $\mathrm{~S}$ \\
\hline
\end{tabular}

$\mathrm{S}=$ Significant $(\mathrm{p}<0.05)$

NS-Not significant $(p>0.05)$

A total of 3380 patients were admitted in one year time period. Outs of these 79 patients were diagnosed as having placental abruption giving a prevalence rate of $2 \%$ in the hospital population. Fetal complications observed were intra uterine demise, fetal growth retardation, preterm labour and fetal anemia. Long term sequel could not be observed due to lack of follow up. We noticed a statistically significant higher prevalence of IUD, PTL and Fetal anemia in women who had abruption of Grade 3-4. Statistically significant number $(p<0.05)$ of fetuses were alive and healthy at the time of birth in mild degree of abruption as compared to severe abruption (Table 1). Although mild degree of abruption does lead to IUGR but this is not significant as compared to severe degree.

\section{Discussion}

Incidence of abruption placenta varies from 0.49. $1.8 \%{ }^{8.9 .10 .11}$. We noticed $2 \%$ prevalence of this condition in our study population, which is slightly higher. Green et-al has shown that $48 \%$ of abruptions are mild, $27 \%$ are moderate and $2-4 \%$ had severe abruption ${ }^{12}$. We noticed that $24 \%$ of our patients had Grade $0-1$ degree of abruption and $75 \%$ had Grade 2-3 degree of abruption.

Diagnosis of this condition is usually made on clinical grounds but Ultrasonography may be helpful. Although it is not a sensitive method of diagnosing abruptio placentae ${ }^{4}$. We used clinical criteria as defined by high-risk pregnancy to categorize different degrees of abruption? ${ }^{7}$.

Pregnancy with abruption is at high risk. As reported by Green et-al it is associated with very high perinatal mortality and morbidity and is the most common cause of intrapartum fetal death. It accounts for $15 \%$ of perinatal mortality ${ }^{12}$. According to Chamberlain and Okonofna perinatal mortality varies from $14.4 \%$ to $67.3 \%{ }^{11.13}$. We were not able to calculate the PNM due to the lack of postnatal follow up but we found IUD, PTL, IUGR, and fetal anemia as the short term complications in patients with placental abruption (Table-1). When comparison was made statistically significant number of fetuses were preterm, anemic and had IUD in Group-2 (Table-1). This revealed that severe degree of abruption puts the fetal life at risk. Hurd reported that higher incidence of congenital abnormalities and IUGR contribute to high PNM ${ }^{14}$. We in contrast did not encounter any fetus with congenital abnormality. Similarly IUGR was not significantly high in group-2

Prematurity was the most common contributory factor for increased fetal morbidity in our study. A conservative management can be appropriate to avoid the risk of prematurity as PNM is closely related to gestation 15. We reached at the conclusion that observation rather than prompt delivery should be considered in Grade $0-1$ if the fetus is grossly immature as the prevalence of fetal anemia and IUD is low in this group and fairly large number of fetuses are delivered in a good condition (Table-1).

\section{Conclusion}

We reached at the conclusion that Abruptio placenta can result in significant morbidity and mortality of the fetus in terms of prematurity, fetal anemia, IUGR and IUD. This morbidity varies with different grades of abruption. Severe degree of abruption adversely effects the fetal outcome as compared to abruption of mild degree. However mild degree of abruption is associated with good fetal outcome as compared to severe abruption $(\mathrm{p}<0.05)$. Therefore a more aggressive approach is required to manage Group-2 cases and observational strategy should be considered for Group-1 patients. This can give time for fetal maturity and decrease the risks associated with prematurity. Adverse fetal outcome in Group-2 also reflects the poor quality of obstetrical care therefore measures should be taken to improve obstetrical care in this high-risk population. Provision of pediatric squad, continuous cardiotocography, consultant led care and prompt delivery are few measures that can lead to better fetal outcome.

\section{References}

1. Justin C, Konje/ David J, taylor. Bleeding in late pregnancy. In: High risk pregnancy. London: WB Saunders, 1999: 111-28.

2. Naheed I, Kauser S, Begum A, Ashraf H, Tajammul A.Abruptio placentae (study of maternal and fetal outcome). Pakistan Post graduate Med Journal 1998; 9: 104-7.

3. Abu-Heija A, Al chalabi H, El-iloubani N.Abruptio placentae: risk factors and perinatal outcome. J Obstet Gynaecol Res 1998; 24:141-4.

4. Ananth CV, Wilcox AJ. Placental abruption and perinatal mortality rate in United states. Am J Epidemiol 2001; 153:332-7.

5. Ozumba BC. Abruptio placentae at the University of Nigeria teaching hospital, Enugu: a 3-year study. Aust NZ J Obstet Gynaecol 1989; 29:117-20. 
6. Ananth CV, Berkowitz GS, Saritz DA, Lapinski RH, Placental abruption and adverse perinatal outcome. JAMA 1999; 282: 1646-51.

7. Sher G, Statland BE. Abruptio placentae with coagulopathy: a rational basis for management. Clinical Obstetrics and Gynaecology 1985; 28: 15-23.

8. Chamberlain GVP, Philip E, Howlette B, Masters K. (1978) British Births, 1970. London: Heinemann.

9. Pritchard JA. Genesis of severe abruptio. Am J Obstet and Gynaecol 1970; 108: 22-27.

10. Paintin DB. The epidemiology of antepartum hemorrhage: a study of all births in a community. Journal of obstetrics and gynaecology of the British common wealth 1962; 69: 614-623.

11. Knab DR. Aburptio placentae: An assessment of the time and method of delivery. Obstetrics and Gynaecology 1978; 52:625-629.
12. Green JR. Placental abnormalities, placenta previa and abruptio placenta. In: Maternal and fetal medicine. Philadelphia: WB Saunders, 1984; 539.

13. Rivera-Alxima ME, Saldana LR, Maklad N, Krops S. The use of ultrasound in expectant management of abruptio placenta. American J Obstet and Gynaecol 1985; 1983: 146: 924-927.

14. Hurd WW, Moidovnik M, Lavin JP. Selective management of abruptio placenta: A prospective study. Obstetrics and Gynaecology 1983; 53: 270-72.

15. Feinkind L, Nanda D, Delike I, Minkoff H. Abruoptio placenta after percutaneous umblical cord sampling: A case report. Am J Obstet and Gynaecol 1990;162: 1203-4. 